\title{
A CROSS-SECTIONAL STUDY ON SELF-MEDICATION PRACTICES AND MEDICATION ADHERENCE AMONG KASHMIRI URBAN POPULATION
}

\author{
SHAKEEL AHMAD MIR* \\ Department of Clinical Pharmacology, Sher-I-Kashmir Institute of Medical Sciences, Srinagar, Jammu and Kashmir, India. \\ Email: drshakeelahmadmir@gmail.com
}

Received: 25 January 2018, Revised and Accepted: 20 February 2018

\section{ABSTRACT}

Objectives: Self-medication has been adopted worldwide. It is voluntarily chosen by the consumers as it has social and economical benefits. For selfmedication to be successful, adherence is an important factor. Adherence to medications is associated with improved clinical outcomes and reduced morbidity and mortality. The objectives of the present study are to assess the prevalence, pattern, and adherence of urban population of Kashmir to self-medication.

Methods: A total of 200 participants were included in this questionnaire-based study by convenience sampling. Informed written consent was taken from each participant in this study. Consenting participants anonymously completed the questionnaire. Only 176 returned the completed questionnaire, 18 participants denied any self-medication practice and their data were not further analyzed. Data of 158 participants were analyzed by manual calculators, VassarStats, and SPSS (V20). Results are expressed in frequencies and percentages.

Results: The study population consisted of $65.18 \%$ males $94.12 \%$ were literate $84.57 \%$ self-medicated for fever and respiratory symptoms, $3.79 \%$ for skin-related symptoms, $5.06 \%$ for urinary symptoms, $4.43 \%$ for oro dental conditions, and 5.69\% for gastrointestinal symptoms. $89.87 \%$ purchased the drugs from the pharmacy, and $10.12 \%$ used leftover drugs. Only $26.58 \%$ used the drugs until apparent full recovery. $51.28 \%$ stopped the drugs as soon as symptoms disappeared. $12.65 \%$ stopped the drugs after few days. $6.32 \%$ had a mixed behavior. $25.31 \%$ consulted pharmacist for advice, $10.75 \%$ received advice from family and friends, and $43.03 \%$ collected information from internet, print, and electronic media.

Conclusion: Self-Medication is practiced worldwide. It has many advantages to benefit from the practice, adherence is an essential factor. Poor adherence may make it less useful and even a harmful practice.

Keywords: Self-medication, Medicine, Behavior, Adherence, Kashmir, Pattern.

(c) 2018 The Authors. Published by Innovare Academic Sciences Pvt Ltd. This is an open access article under the CC BY license (http://creativecommons. org/licenses/by/4. 0/) DOI: http://dx.doi.org/10.22159/ajpcr.2018.v11i6.24942

\section{INTRODUCTION}

Self-medication involves the use of medicinal products by the individuals to treat self-recognized diseases or symptoms or the intermittent or continuous use of medication prescribed by a physician for chronic or recurrent disease or symptoms [1]. Self-medication also involves acquiring medicines without a prescription or resubmitting old prescriptions to purchase medicines, sharing medicines with relatives or members of one's social circle or using leftover medication [2].

Self-medication is becoming an increasingly important area within health care. It moves patients toward greater independence in making decisions about management of minor illnesses, thereby promoting empowerment [3]. Improvements in people's general knowledge, level of education, and socioeconomic status form a basis for successful selfmedication [4].

The concept of self-medication has been adopted worldwide. In Britain and United States, on the average $50-75 \%$ of health-care takes place within the realm of self-medication [5]. The prevalence rate is up to 68\% in European countries, 31\% in Urban India, 59\% in Nepal, 51\% in Pakistan, $92 \%$ in adolescents of Kuwait, and $47.8 \%$ in Southern China [6].

To use a non-prescription product safely and effectively, the consumer must recognize the symptoms accurately, set therapeutic objectives, select a product to be used, determine an appropriate dosage and dosage schedule, taking into account the person's medical history, contraindications, concomitant diseases, and concurrent medications, and monitor the response to the treatment and possible adverse effects [4].

Patient adherence to a medication regimen is central to good outcomes. Medication adherence usually refers to whether the patient takes his medications as prescribed, as well as whether he continues to take prescribed medication. Medication non-adherence is a growing concern because of mounting evidence that it is prevalent and associated with adverse outcomes and higher costs of care [7].

Although several studies have been carried out in different populations to evaluate the practice of self-medication, there is a paucity of studies on adherence during self-medication.

The present study was undertaken to identify a pattern of selfmedication and adherence to treatment in an urban population of Kashmir.

\section{METHODS}

The present work is a cross-sectional study and was carried out among the general urban population. A total of 200 participants were included in the study by convenience sampling method. Respondents with emotional, psychiatric, and intellectual disturbances were excluded because these conditions could affect the reliability of their response. After an extensive literature review, a self-developed, pre- validated questionnaire consisting of both open-ended and close-ended questions about self-medication was used. The Morisky Medication Adherence Scale (Kashmiri and Urdu translation) was used to collect 
the data for medication adherence. The participants were informed about the objective of the study, and the procedure of completing the questionnaire was explained. Informed written consent was taken from each participant in this study. Consenting participants anonymously completed the questionnaire. Only 176, returned the completed questionnaire, 18 participants denied any self-medication practice and their data were not further analyzed. The analysis was done by manual calculators, VassarStats, and SPSS (V20). Results are expressed in frequencies and percentages.

\section{RESULTS}

The Table 1 shows that study population consisted of $65.18 \%$ males and $34.81 \%$ females. $94.12 \%$ were literate. $84.57 \%$ self-medicated for fever, myalgia, and respiratory symptoms. $3.79 \%$ resorted to the practice of self-medication for dermatological symptoms/diseases, 5.06\% for urinary symptoms, $4.43 \%$ for oro dental conditions and $5.69 \%$ for diarrhea, and other gastrointestinal (GI) symptoms. 89.87\% purchased the drugs from the pharmacy and $10.12 \%$ used leftover drugs or shared the drugs their friends/family had used earlier for similar symptoms. Only $26.58 \%$ used the drugs until apparent full recovery. $51.28 \%$ stopped the drugs as soon as symptoms disappeared. $12.65 \%$ stopped the drugs after few days irrespective of response. $3.16 \%$ continued the drug for prolonged period, and $6.32 \%$ had a mixed behavior. $25.31 \%$ consulted pharmacist for advice, $10.75 \%$ received advice from family and friends, and $43.03 \%$ collected information from internet, print, and electronic media. $20.88 \%$ made a guess about the drug, dose, and

Table 1: Various parameters of self-medication and adherence

\begin{tabular}{|c|c|}
\hline Variable & n (\%) \\
\hline \multicolumn{2}{|l|}{ Sex } \\
\hline Males & $103(65.18)$ \\
\hline Females & $55(34.81)$ \\
\hline \multicolumn{2}{|l|}{ Education } \\
\hline Illiterate & $09(5.69)$ \\
\hline Literate & $149(94.30)$ \\
\hline School level & $103(69.12)$ \\
\hline College level & $38(25.50)$ \\
\hline University level & $08(5.36)$ \\
\hline \multicolumn{2}{|l|}{ Diseases/symptoms treated* } \\
\hline Fever, cough, cold, sore throat & $148(84.57)$ \\
\hline Dermatological & $06(3.79)$ \\
\hline Urinary & $08(5.06)$ \\
\hline Oro dental & $07(4.43)$ \\
\hline GI & $09(5.69)$ \\
\hline \multicolumn{2}{|l|}{$\begin{array}{l}\text { *Due to multiple options respondents } \\
\text { could select, sum of percentage is more } \\
\text { than } 100\end{array}$} \\
\hline \multicolumn{2}{|l|}{ Source of the drug } \\
\hline Pharmacy & 142 (89.87) \\
\hline Leftovers/family/friends & $16(10.12)$ \\
\hline \multicolumn{2}{|l|}{ Adherence behavior } \\
\hline $\begin{array}{l}\text { Stopped the drug after apparent full } \\
\text { recovery }\end{array}$ & $42(26.58)$ \\
\hline $\begin{array}{l}\text { Stopped the drug after symptoms } \\
\text { disappeared }\end{array}$ & $81(51.26)$ \\
\hline $\begin{array}{l}\text { Stopped the drug after few days } \\
\text { irrespective of response }\end{array}$ & $20(12.65)$ \\
\hline $\begin{array}{l}\text { Continued till purchased drug last } \\
\text { irrespective of response }\end{array}$ & $05(3.16)$ \\
\hline Stopped randomly & $10(6.32)$ \\
\hline \multicolumn{2}{|l|}{ Major source of advice } \\
\hline Pharmacy & $40(25.31)$ \\
\hline Friends/family & $17(10.75)$ \\
\hline Internet/print and electronic media & $68(43.03)$ \\
\hline Self-guess/other & $33(20.88)$ \\
\hline \multicolumn{2}{|l|}{ Morisky medication adherence scale score } \\
\hline Poor adherence & $110(69.62)$ \\
\hline Moderate adherence & $31(19.62)$ \\
\hline Good adherence & $17(10.75)$ \\
\hline
\end{tabular}

duration. Regarding Morisky medication adherence scale score, only $10.75 \%$ respondents showed a good medication adherence. Majority of the respondents (69.62\%) showed poor adherence.

\section{DISCUSSION}

Self-medication involves the use of medicinal products by the consumer to treat self-recognized disorders or symptoms, or the intermittent or continued use of a medication prescribed by a physician for chronic or recurring diseases or symptoms. In practice, it also includes the use of the medication of family members, especially where the treatment of children or the elderly is involved [4].

There has been a growing realization that personal self-care and selfmedication in the community should be the starting point of health care, and is, in fact, the foundation for people to manage life-long health [8]. In a world of scarce government and individual resources, responsible self-medication should be a cornerstone of health-care provision and health policy [9].

Self-medication provides low-cost alternative for expensive medical management, but inappropriate use can cause problems. In spite of the shortcomings, individual attitude to self-medication has not diminished. Various studies conducted worldwide revealed the prevalence of 60$90 \%[5]$

For the self-medication to be successful, adherence is one of the most important factors. Nowadays, non-adherence is main concern for all those involved in the health-care delivery system [7].

It has been found that, in developed countries, adherence among patients suffering chronic diseases averages only $50 \%$. The magnitude and impact of poor adherence in developing countries are assumed to be even higher. Good adherence improves the effectiveness of interventions aimed at promoting healthy lifestyles [10].

The present study was taken up to evaluate the self-medication pattern and adherence to it in urban areas of Kashmir. The overall prevalence rate of self-medication found in the present study was $89.77 \%$, which is comparable to that found in rural areas of Kashmir (89.58\%) [6]. $65.18 \%$ of those who practiced self-medication were males. Most of the self-medicators were literate $(94.30 \%)$, out of which $69.12 \%$ had studied up to high or higher secondary level. Various studies have shown that self-medication is higher in literate people as compared to illiterate [11].

The common symptoms/diseases for which the practice of selfmedication was adopted were: Fever, cough, cold, sore throat, myalgia (84.57\%), GI (5.69\%), and oro dental (4.43\%).

In another study, $20.2 \%$ respondent self-medicated for respiratory tract infections, $23.7 \%$ GI diseases, $23.6 \%$ headache, fever, and $10 \%$ for miscellaneous diseases/symptoms [12].

In one more study, self-medication was used in mostly cough and cold $(61 ; 43 \%)$, body pain $(45 ; 32 \%)$, GI complaints $(44 ; 31 \%)$, and fever $(40 ; 29 \%)[13]$.

In the present study, the pharmacy was the major source of drugs $(89.87 \%)$.

These results are similar to another study in which, the most common sources of drugs were pharmacy $(80 ; 57 \%)$, relatives and friends $(45$; $32 \%)$, leftovers $(31 ; 22 \%)$, home pharmacy $(11 ; 8 \%)$, and previous prescriptions $(8 ; 6 \%)$ [13].

Another study conducted in Mumbai India showed that $85 \%$ respondents practice self-medication. The respondents found selfmedication to be time-saving, economical, convenient and providing quick relief in common illnesses [14]. 
Another study conducted in Karnataka, India, found that the prevalence of self-medication was $47 \%$. Factors such as gender, recent experience of an illness, and stocking medicines at home were found significantly associated with self-medication practice [15]

Regarding the important issue of adherence, the present study results reveal that only $26.58 \%$ continued the drug till apparent full recovery. Majority (51.28\%) stopped the drug as soon as the major symptom(s) for which the drug was taken, disappeared. 12.65\% stopped the drug after few days irrespective of the response. On Morisky medication adherence scale score, only $10.75 \%$ respondents showed a good medication adherence. Majority of the respondents (69.62\%) showed poor adherence.

Poor medication adherence (11.1\%) has also been reported by Hummara et al. in a study in Quetta, Pakistan [16]. Typical nonadherence to medication is $50 \%$. It has been observed that even after some critical conditions like myocardial infarction, almost one-fourth of patients $(24 \%)$ do not even fill their cardiac medications by day 7 of discharge [17]. Another study perceived the high magnitude of self-medication among medical students associated with low level of adherence [18].

\section{CONCLUSIONS}

Self-care practices including self-medication are nearly universal among patients. Self-medication empowers patients by giving them independence to treat minor illnesses. This reduces the pressure of medical services, especially where health-care services are insufficient. Adherence is among most important factors for self-medication to be successful. Nonadherence can halt the improvement of a patient's condition and even can worsen it. Its costs are both personal and economic.

\section{AUTHORS CONTRIBUTIONS}

There are only a few studies on self-medication practices among Kashmiri population. The present study, though exploratory in nature, reveals that self-medication is a common practice among Kashmiris and medication adherence is mostly poor.

\section{CONFLICTS OF INTEREST}

The author has no conflicts of interest to disclose.

\section{REFERENCES}

1. The Role of Pharmacist in Self-Care and Self-Medication. Report of the Fourth WHO Consultative Group on the Role of Pharmacist.
Available from: http://www.apps.who.int/medicinedocs/pdf/whozip32e/ whozip32e.pdf.

2. Loyola Filho AI, Lima-Costa MF, Uchôa E. Bambuí project: A qualitative approach to self-medication. Cad Saude Publica 2004;20:1661-9.

3. Hughes CM, McElnay JC, Fleming GF. Benefits and risks of selfmedication. Drug Saf 2001;24:1027-37.

4. World Health Organization(W.H.O). Guidelines for the Regulatory Assessment of Medicinal Products for Use in Self-Medication; 2000. Available from: http://www.apps.who.int/medicinedocs/pdf/s2218e/s2218e. pdf.

5. Afolabi AO. Self-medication, drug dependency and self-managed health care-a review. In: Maddock J, editor. Public Health-Social and Behavioral Health. Rijecka, Croatia: Intech; 2012.

6. Mir SA. Prevalence and pattern of selh-medication practices in rural areas of Central Kashmir. Int J Pharm 2015;5:1255-60.

7. Michael DB. Medication adherence: Patient education, communication and behaviour J Malta Coll Pharm Pract 2012;18:1-5.

8. World Self-Medication Industry(WSMI).The story of self-care and Self-Medication. 40 Years of Progress, 1970-2010. Available from: http://www.wsmi.org/wp-content/data/pdf/storyofselfcare_brochure. pdf.

9. Sonam J, Reetesh M, Jeetendra KP. Concept of self-medication: A review. Int J Pharm Biol Arch 2011;2:831-6.

10. World Health Organization(W.H.O). Adherence to Long-Term Therapies Evidence for action; 2003. Available from: http://www.who. int/chp/knowledge/publications/adherence_report/en.

11. Verma RK, Mohan L, Pandey M. Evaluation of self-medication among professional students in North India: Proper statutory drug control must be implemented. Asian J Pharm Clin Res 2010;3:60-4.

12. Pankaj J, Ajay S, Rajiv K, Pankaj A. Statistical study on self-medication pattern in Haryana, India. Indo Glob J Pharm Sci 2012;2:21-35.

13. Dnyanesh L, Vaidehi L, Gerard K, Gerhard F. A systematic review of the literature to assess self-medication practices. Ann Med Health Sci Res 2017:7:1-14

14. Vanita DS, Mamta SP. A study of prevalence of self-medication practice among people of Mumbai. India. Int J Pharm Pharm Sci 2015;7:19-23.

15. Pranav V, Narayanan P, Guddattu V. Self-medication practice among urban slum dwellers in Udupi Taluk, Karnataka, India. Int J Pharm Pharm Sci 2017;9:53-6.

16. Hummara S, Noman UH, Suhail R, Aqeel N, Muhammad SZ. Assessment of medication adherence among noncommunicable chronic disease patients in Quetta, Pakistan: Predictors of medication adherence. JAMA 2017;4:1-9.

17. Jackevicius CA, Li P, Tu JV. Prevalence, predictors, and outcomes of primary nonadherence after acute myocardial infarction. Circulation 2008; $117: 1028-36$

18. Shammin H, Nazmun NA, Sumaiya M, Sultan N. Association between Self-Medication behavior and adherence among medical students in Dhaka, Bangladesh. Am J Psychiatry 2017;11:S346-52. 